\title{
Effectiveness of peer counseling and membership in breastfeeding support groups in promoting optimal breastfeeding behaviors in the Philippines
}

\author{
Ofelia P. Saniel ${ }^{1,2^{*}}$ (D) Veincent Christian F. Pepito ${ }^{1,3}$ and Arianna Maever L. Amit ${ }^{1,3}$
}

\begin{abstract}
Background: The prevalence of early initiation of breastfeeding and exclusive breastfeeding (EBF) at 6 months remain low in the Philippines. To help meet the 90\% early initiation of breastfeeding target and to improve infant and young child feeding practices in the Philippines, the Millennium Development Goals - Fund 2030 Joint Programme (JP) on Ensuring Food Security and Nutrition for Children 0-24 months old was implemented. We aimed to determine the effectiveness of visits by peer counselors during pregnancy and after delivery, and membership in breastfeeding support groups in promoting these optimal breastfeeding practices.

Methods: We used data from the Endline Survey of the JP to study the effects of prenatal and postnatal peer counselor visits, and membership in breastfeeding support groups, and their possible interactions with initiation of breastfeeding within 1 hour of birth among children aged 0 to 24 months and EBF at 6 months among children aged 6 to 24 months, while adjusting for confounding. We used logistic regression methods for survey data to assess these associations.

Results: Of the 2343 mother-infant pairs, only 1500 (63.1\%) practiced early initiation of breastfeeding. Of the 1865 children aged 6 months or older, only 621 (34.7\%) were exclusively breastfed at 6 months. After adjusting for confounding variables, there was no strong evidence that peer counselor visits were associated with early initiation or EBF at 6 months. However, members of breastfeeding support groups had 1.49 times higher odds of early initiation of breastfeeding (95\% Cl [Confidence Interval] 1.12, 1.98) and 1.65 times higher odds of EBF $(95 \% \mathrm{Cl} 1.20$, 2.24) compared to those who were not members of breastfeeding support groups. There was no interaction between the different exposure variables and early initiation and EBF at 6 months.

Conclusions: Our findings suggest breastfeeding support groups may be institutionalized to promote both early initiation of breastfeeding and EBF in the Philippines, while the role of peer counselors in promoting optimal breastfeeding behaviors should be further reviewed. Our suggestion to integrate non-healthcare professionals to promote early initiation of breastfeeding and EBF could be tested in future intervention studies.
\end{abstract}

\footnotetext{
* Correspondence: opsaniel@up.edu.ph

${ }^{1}$ College of Public Health, University of the Philippines Manila, 625 Pedro Gil

St., Ermita, Manila, Philippines

${ }^{2}$ Symmetrix Research Consultancy Company, Manila, Philippines

Full list of author information is available at the end of the article
}

(c) The Author(s). 2021 Open Access This article is licensed under a Creative Commons Attribution 4.0 International License, which permits use, sharing, adaptation, distribution and reproduction in any medium or format, as long as you give appropriate credit to the original author(s) and the source, provide a link to the Creative Commons licence, and indicate if changes were made. The images or other third party material in this article are included in the article's Creative Commons licence, unless indicated otherwise in a credit line to the material. If material is not included in the article's Creative Commons licence and your intended use is not permitted by statutory regulation or exceeds the permitted use, you will need to obtain permission directly from the copyright holder. To view a copy of this licence, visit http://creativecommons.org/licenses/by/4.0/. The Creative Commons Public Domain Dedication waiver (http://creativecommons.org/publicdomain/zero/1.0/) applies to the data made available in this article, unless otherwise stated in a credit line to the data. 
Keywords: Millennium Development Goals, Breastfeeding support group, Peer counselor, Early initiation of breastfeeding, Exclusive breastfeeding, Breastfeeding, Pediatrics, Philippines

\section{Background}

Early initiation of breastfeeding, defined as breastfeeding within $1 \mathrm{~h}$ of birth, and exclusive breastfeeding (EBF), defined as giving the infant breastmilk only, without supplementary food or water or medicines, during the first 6 months of life, are optimal breastfeeding behaviors that improve child health and survival [1-5]. Early initiation of breastfeeding also stimulates the production of breastmilk, provides antibody protection, and reduces postpartum hemorrhage [6]. Further, it is linked with successful practice of other optimal breastfeeding behaviors, such as EBF for 6 months after birth, and continued breastfeeding for at least 2 years with complementary feeding after 6 months $[5,7,8]$. Longer duration of EBF significantly improves motor and cognitive development $[9,10]$, and prevents diarrhea, acute respiratory infections, and fever among infants. Exclusive breastfeeding also reduces the burden of undernutrition in the community [11]. In addition to the direct benefits of optimal breastfeeding behaviors on infants, breastfeeding also benefits mothers. In the short term, breastfeeding reduces maternal bleeding and stress after delivery, facilitates positive metabolic changes and postpartum weight loss, and delays ovulation. In the long term, breastfeeding increases postpartum weight loss, decreases visceral adiposity, and reduces risk of cardiovascular diseases, diabetes, and breast and ovarian cancers [12].

Despite the benefits of early initiation of breastfeeding and EBF, their prevalence is low in many countries, including the Philippines. The overall prevalence of early initiation of breastfeeding was only $57.6 \%$, in 24 countries included in the World Health Organization (WHO) Global Survey on Maternal and Perinatal Health in 2004 to 2008. The same survey also reported that the Philippines ranked among the lowest, with an early initiation of breastfeeding prevalence of only 39.9\% [6]. Meanwhile, there has been little progress in improving the practice of exclusive breastfeeding. As of 2015, only $40 \%$ of children worldwide were exclusively breastfed [13]. The Philippine National Demographic and Health Surveys reported that the prevalence of early initiation of breastfeeding within the first hour of life in the country was $54.0 \%$ in 2003 and $53.5 \%$ in 2008 , while the prevalence of EBF, defined as the proportion of infants under 6 months of age who were given only breastmilk, were $33.5 \%$ and $34.0 \%$, respectively [8]. However, the 2013 Philippine National Demographic and Health Survey reported that the prevalence of early initiation of breastfeeding in the country further decreased to $49.0 \%$
[14]. These figures are far from the targeted $90 \%$ prevalence of early initiation of breastfeeding and the $70 \%$ prevalence of EBF under 6 months of age set by the Philippine Department of Health (DOH) by 2016 [8].

To help meet these targets and to improve infant and young child feeding (IYCF) practices in the Philippines, the WHO, the United Nations Children's Fund (UNICEF), the Food and Agriculture Organization (FAO), the International Labor Organization (ILO), and the World Food Program (WFP), in collaboration with the $\mathrm{DOH}$, launched in 2009 the Millennium Development Goals - Fund 2030 Joint Programme (MDG-F JP) on Ensuring Food Security and Nutrition for Children 0-24 months old in the Philippines. The overall aim of the Programme was to accelerate the attainment of Millennium Development Goals (MDGs) 1 and 4, which focused on reducing undernutrition among children and decreasing child mortality, respectively. Other key outcomes of the JP were increased prevalence of EBF by $20 \%$ annually, reduced prevalence of undernutrition by $3 \%$, and improved capacities of national and local government units and stakeholders to formulate, promote, and implement IYCF policies and programs. To attain these outcomes, several intervention projects were implemented including the engagement and training of volunteer breastfeeding peer counselors and the establishment of breastfeeding support groups to encourage mothers to practice optimal breastfeeding during pregnancy and after childbirth. After the JP implementation, an external agency conducted a cross-sectional study between 2012 and 2013 to assess the outcomes and impact of the Programme. A $0.7 \%$ reduction in the prevalence of undernutrition and 7.7\% increase in the prevalence of EBF were recorded after the implementation of the JP interventions; however, both figures were far from the JP targets. The same cross-sectional study also reported that the prevalence of early initiation of breastfeeding was $62.8 \%[15,16]$. While an impact evaluation study has been conducted to assess the overall effectiveness of the JP, the effectiveness of component projects like the JP-trained peer counselors and the breastfeeding support groups in promoting early initiation of breastfeeding and EBF among target mothers is unknown.

Previous studies showed that the determinants of early initiation of breastfeeding include knowledge about optimal feeding practices $[17,18]$, mother's age $[17,19,20]$, mother's and partner's employment status [21-23], and exposure to breastfeeding information during pregnancy 
$[17,24]$. Other factors associated with early initiation of breastfeeding are place of delivery, birth attendant, mode of delivery [18, 20, 23], and knowledge about breastfeeding $[18,25]$. A previous study in the Philippines reported that after adjusting for confounding variables, first breastfeed in infants from mistimed pregnancies was much later than infants from planned pregnancies among households with low socioeconomic status [26]. A systematic review on the topic confirmed the role of the aforementioned determinants on early initiation of breastfeeding. Other factors such as place of residence, educational attainment of the parents, socio-economic status, and infant's sex were reported to be important determinants as well $[27,28]$. The determinants of EBF, on the other hand, include mother's marital status, mode of delivery $[29,30]$, economic independence, maternal age, number of children, socio-economic status, maternal HIV status, and birthweight of infant [31, 32]. Having antenatal care, maternal education, and maternal employment were associated with lower odds of exclusive breastfeeding [32]. The same set of variables was also found to be associated with EBF in two systematic reviews, in addition to place of residence, religion, rooming-in, pre-lacteal feeding, advice from relatives and peer-pressure, infant's sex, maternal smoking, and exposure to advertisements about breast milk substitutes [27, 33].

Although some studies on the determinants of early initiation of breastfeeding and breastfeeding duration have been conducted in the Philippines [26, 34], this is the first study, in our knowledge, to explore the effectiveness of specific interventions to promote early initiation of breastfeeding and EBF in the country. This paper's aim was to examine the independent association of peer counseling and membership in breastfeeding support groups in promoting early initiation of breastfeeding within an hour of birth and EBF at 6 months in the six JP sites. In addition, we explored whether there was an interaction (or synergy) between peer counseling and membership in breastfeeding support groups to assess their joint effects on levels of early initiation of breastfeeding within an hour of birth and EBF at 6 months.

\section{Methods}

\section{Research design and study population}

The evaluation of the Joint Programme utilized a 'before-and-after' non-experimental type of study design. A baseline survey was carried out in early 2011 to establish the baseline levels of child undernutrition and prevalence of optimal breastfeeding practices [35]. Subsequently, the interventions were implemented in April 2011 to September 2012, shortly after the Baseline Survey. The Endline Survey was conducted in late 2012 to assess the effectiveness of JP interventions in improving the prevalence of optimal breastfeeding practices and in reducing undernutrition among the target children. We used data from the Endline Survey to examine the independent associations and possible interactions of two particular JP interventions (i.e., the peer counselors and the mother's membership in breastfeeding support groups) with early initiation of breastfeeding and EBF among the target mothers.

There were six JP implementation sites in the Philippines: the cities of Naga, Iloilo, and Zamboanga, and the municipalities of Ragay in Camarines Sur; Carles in Iloilo; and Aurora in Zamboanga del Sur. A stratified twostage systematic random sampling was employed to select the study participants. The barangays or villages in each city/municipality served as the primary sampling units (PSU), which were selected systematically with probability proportional to the PSU's population size. Prior to sampling for the Endline Survey, 44 barangays in Zamboanga City were excluded because of security problems. From each remaining PSU, children less than 2 years old were randomly selected, with equal probability, using the lists of eligible children in each barangay. The lists of eligible children from each barangay were collected from local health workers and validated and updated for completeness by mappers/validators employed by the Endline Survey research team.

A sample size of 2584 mother-infant dyads from all six JP sites was required to detect a $3 \%$ absolute decrease, from the baseline, in the prevalence of underweight for age, using a 0.05 level of significance, $80 \%$ power, a design effect of 1.2 , and an allowance of $10 \%$ for nonparticipation. However, only mothers who were the actual caregivers of the target children were included in our analyses. Data from other child caregivers, such as fathers, were excluded to minimize the effect of different qualities of recall that may arise from having different types of child caregivers. In the analysis for the outcome on EBF at 6 months, we only included infants aged at least 6 months since they were the only ones with data for the outcome of interest. Those younger than 6 months were excluded in the analysis for EBF as they were no longer followed for the outcome of interest.

\section{Operational definition of study variables and description of interventions of interest}

The outcome variables in this study were early initiation of breastfeeding within $1 \mathrm{~h}$ of birth and EBF at 6 months. Infants were categorized based on the time of breastfeeding initiation: early initiation for those who were breastfed within $1 \mathrm{~h}$ of birth and late initiation for those who were breastfed $1 \mathrm{~h}$ after birth. For EBF at 6 months, mothers were asked at what age, in months, solid foods or other liquids were first introduced to the infant. We dichotomized this variable into mothers who 
gave solid/liquid foods to the child 6 months after birth and mothers who did not.

The exposure variables in this study were home visit/s by a peer counselor during the mother's prenatal period, home visit/s by a peer counselor after delivery, and membership of the mother in a breastfeeding support group during the index pregnancy. Being visited by a peer counselor during the prenatal period and membership of the mother in a breastfeeding support group during the index pregnancy were considered as exposure variables in the model for early initiation of breastfeeding. For EBF, we considered these two variables, together with home visit/s by a peer counselor after delivery as our exposure variables. All three are dichotomous variables (either visited by a peer counselor before and after delivery or not, and member of a support group or not). Details on the mobilization of peer counselors and breastfeeding support groups are presented in Additional file 1 . The probable confounders in these associations of interest included place of residence, age of mother in years, total monthly household income, employment status of mother and partner, number of people living in household, number of living older siblings, mode of delivery of index child, birth attendant of index child, place of delivery, sex of child, maternal knowledge score, attendant during prenatal services, month of first prenatal service, and membership in the Pantawid Pamilyang Pilipino Program (4Ps). The 4Ps is a conditional cash transfer program implemented by the Philippine government which targets low-income Filipino families in return for complying with a set of conditions on children's education and the family's utilization of health services such as prenatal check-up and child vaccination [36]. In the model for EBF, early initiation of breastfeeding was also considered as a probable confounder.

\section{Data management and analysis}

Data quality checks, such as checks for duplicates and range checks were performed on the dataset prior to any analysis. Quantitative variables, including age and monthly income, were recoded to allow the assessment of possible linear trends in the association between these variables and the outcome [37]. Some categorical variables were recoded to ensure that each stratum would have sufficient number of observations. Maternal knowledge score was aggregated from seven yes-no questions. Incorrect answers or "don't know" answers were coded as incorrect and given a ' 0 ' score, and ' 1 ' for each correct answer. Scores ranged from 0 to 7 , with higher scores implying better maternal knowledge. Lastly, variables that may be correlated were combined, such as marital status of the mother and employment status of partner. No observations were removed at any point in the analysis to ensure that standard errors can be computed correctly.

The exposure variables were cross-tabulated with each of the two outcome variables and the association of each of these exposures with each outcome variable were tested with Pearson's $x^{2}$ test for categorical exposures, adjusted Wald test for normally distributed continuous variables, or Wilcoxon rank-sum test for skewed continuous variables. The distribution of missing data was shown for each variable but were not included in estimating the $p$-values. For each of these associations, crude odds ratios (cORs) were estimated using simple logistic regression for survey data. As part of screening potential confounders, each probable confounder and the outcome variable were cross-tabulated with each of the exposure variables using similar statistical tests as described above. Prior to doing multivariable analyses, observations with missing data for any of the variables of interest were excluded from the analysis. We used logistic regression methods for both early initiation of breastfeeding and EBF. Details of building the final models are presented in Additional file 2.

A level of significance of 0.05 was used in all analyses, and 95\% Confidence Intervals (CIs) were reported. Data management and analyses were carried out in Stata 14.2 [38].

\section{Results}

A total of 2542 parent-infant dyads were interviewed in the Endline Survey, giving a $98.4 \%$ response. Of these, only $2343(93.1 \%)$ of the households had mothers who served as infant caregiver and were thus included in the analyses. Majority (77.6\%) of the mothers were from urban areas. The mothers were between 15 and 50 years old, and most were married or living with their partners (92.2\%). Most (92.3\%) mothers were employed. During their index pregnancy, some of them $(23.5 \%)$ were visited by a peer counselor and/or were reported as members of a breastfeeding support group (33.4\%). When they gave birth to the index child, most of them (67.0\%) delivered in health facilities and were attended by skilled professional birth attendants (75.4\%). Some of them (28.5\%) were also visited by peer counselors after delivery. Lastly, only $63.1 \%$ of mothers have initiated breastfeeding within an hour of birth. Out of the 2343 households who had mothers who served as the infant caregiver, 1865 (79.9\%) were aged 6 months old or older. Out of this, only $34.7 \%$ had exclusively breastfed their children for 6 months (Table 1).

The distribution of the mothers' age of gestation at their first prenatal checkup was right-skewed as most mothers had their first visit during the first 3 months of pregnancy $($ median $=3)$. The knowledge scores of the respondents ranged from 0 to 7 and these scores were leftskewed in distribution as most mothers had scores of 5 
Table 1 Characteristics of the study participants $(n=2343)$

\section{Variable/Category}

Visit by a peer counselor during prenatal period ${ }^{a}$

No

Yes

Visit by a peer counselor after delivery ${ }^{\mathrm{a}}$

No

Yes

Membership in breastfeeding support groups ${ }^{a}$

No

Yes

Place of residence

Urban area

Rural area

Age of mother in years ${ }^{a}$

15-19

20-24

25-29

30-34

35-39

40-50

Monthly income (PhP)

0-3800

$3801-5999$

$6000-8999$

$9000-15,999$

$16,000+$

Employment status of mother

Employed

Unemployed

Employment status of partner ${ }^{a}$

Employed

Unemployed

Marital status ${ }^{a}$

Married/Living together

Never married/separated/divorced/widowed

Combined variable for marital status and employment status of partner ${ }^{a}$

Single mother

Has employed partner/spouse

Has unemployed partner/spouse

Membership in a conditional cash incentive program of the government (4Ps)

No

Yes

Prenatal care provider ${ }^{\mathrm{a}}$

Doctor/Nurse/Midwife

None/Traditional Birth Attendant
Frequency (\%)

1817 (75.5)

502 (23.5)

1797 (71.1)

$532(28.5)$

1683 (66.3)

650 (33.4)

2091 (77.6)

252 (22.4)

179 (7.2)

634 (26.8)

634 (25.3)

$521(23.9)$

246 (10.9)

$120(5.6)$

469 (21.3)

411 (16.6)

$524(21.0)$

480 (20.8)

$459(20.4)$

2167 (92.3)

$176(7.7)$

2096 (88.7)

85 (3.8)

2176 (92.2)

163 (7.6)

$163(7.6)$

2090 (88.4)

85 (3.8)

1853 (76.8)

487 (23.1)

2271 (96.3)

$61(3.5)$ 
Table 1 Characteristics of the study participants $(n=2343)$ (Continued)

\begin{tabular}{|c|c|}
\hline Variable/Category & Frequency (\%) \\
\hline \multicolumn{2}{|l|}{ Mode of delivery ${ }^{\mathrm{a}}$} \\
\hline Normal & $2139(90.8)$ \\
\hline Caesarean/other & $195(8.6)$ \\
\hline \multicolumn{2}{|l|}{ Birth attendant ${ }^{\mathrm{a}}$} \\
\hline Skilled & $1805(75.4)$ \\
\hline Traditional birth attendant/none/self/relatives/underboard midwife & $512(23.7)$ \\
\hline \multicolumn{2}{|l|}{ Place of delivery ${ }^{a}$} \\
\hline Home-based & $667(32.2)$ \\
\hline Government healthcare facility & $1434(57.4)$ \\
\hline Private healthcare facility & 225 (9.6) \\
\hline \multicolumn{2}{|l|}{ Sex of child } \\
\hline Boy & $1182(51.5)$ \\
\hline Girl & $1161(48.5)$ \\
\hline \multicolumn{2}{|l|}{ Initiation of breastfeeding within one hour of birth ${ }^{\mathrm{a}}$} \\
\hline Early & $1500(63.1)$ \\
\hline Late & $763(35.2)$ \\
\hline \multicolumn{2}{|l|}{ Exclusive breastfeeding at six months ${ }^{\mathrm{a}, \mathrm{b}}$} \\
\hline No & $1155(62.7)$ \\
\hline Yes & $621(34.7)$ \\
\hline
\end{tabular}

${ }^{a}$ Has missing data

${ }^{b} n=1865$ infants who are at least six months old

or higher $($ median $=6)$. The number of living older siblings of the infants in the study ranged from 0 to 13 . The distribution of this variable was right-skewed as the infants generally had few older siblings $($ median $=1$ ). The household size of the respondents ranged from 2 to 25 members. This variable was also right-skewed, as the respondents lived in relatively smaller households (median $=6$ ).

\section{Associations with early initiation of breastfeeding}

Among the probable confounders considered, place of residence, maternal age, monthly income, membership in 4Ps, mode of delivery, birth attendant, and place of delivery were all found to have strong evidence of association with early initiation of breastfeeding. Maternal knowledge score and number of older siblings alive were also found to be significantly associated with early initiation of breastfeeding (Table 2). Without adjusting for confounding, visits by peer counselors during the prenatal period (cOR 1.48; 95\% CI 1.16, 1.88) and membership in breastfeeding support groups (COR 1.56; 95\% CI $1.17,2.08$ ) were significantly associated with early initiation of breastfeeding (Table 3).

Among the probable confounders, place of residence, maternal age, household size, number of older siblings alive, monthly income, mother's employment status, marital status, the combined variable of marital status and partner employment status, membership in 4Ps, birth attendant, and place of delivery were all associated with peer counselor visits during the prenatal period (Additional file 3). Meanwhile, household size, number of older siblings alive, maternal age, and membership in 4Ps were all associated with membership in a breastfeeding support group (Additional file 4). Therefore, place of residence, maternal age, monthly income, membership in 4Ps, birth attendant, place of delivery, and number of living older siblings may confound the association between the exposure variables and early initiation of breastfeeding. However, we forced other variables (e.g., maternal knowledge, mode of delivery, mother's employment status, and sex of child) in our regression model for early initiation of breastfeeding because these variables were found to be 'a-priori' determinants of this outcome in the literature.

In building our final regression model, we used the combined variable for civil status and partner's employment status to minimize missing data. We also detected collinearity between place of delivery and birth attendant, so we combined place of delivery and birth attendant, and used this variable in building our final regression model. To ensure that models were comparable during model-building, we excluded from the multivariable analyses some 316 observations with missing data in any of the remaining variables of interest. Thus, 
Table 2 Cross-tabulations of exposure and probable confounding variables with early initiation of breastfeeding within one hour of birth $(n=2343)$

\begin{tabular}{|c|c|c|c|}
\hline \multirow{2}{*}{$\begin{array}{l}\text { Variable/Category } \\
\text { Visit by a peer counselor during prenatal period }\end{array}$} & \multicolumn{2}{|c|}{ Initiation of breastfeeding $^{a}$} & \multirow{2}{*}{$\frac{p \text {-value }}{<0.01}$} \\
\hline & Late & Early & \\
\hline No & $611(37.3)$ & $1138(60.8)$ & \\
\hline Yes & $147(29.1)$ & $346(70.1)$ & \\
\hline Membership in breastfeeding support groups & & & $<0.01$ \\
\hline No & $580(38.4)$ & $1032(59.6)$ & \\
\hline Yes & $181(29.0)$ & $463(70.1)$ & \\
\hline Place of residence & & & 0.03 \\
\hline Urban area & $707(38.1)$ & $1304(59.8)$ & \\
\hline Rural area & $56(25.3)$ & $196(74.8)$ & \\
\hline Age of mothers in years & & & $<0.01$ \\
\hline $15-19$ & $52(32.3)$ & $119(65.2)$ & \\
\hline $20-24$ & $214(37.0)$ & $402(61.5)$ & \\
\hline $25-29$ & $193(33.3)$ & $426(65.9)$ & \\
\hline $30-34$ & $197(41.8)$ & $303(56.2)$ & \\
\hline $35-39$ & $65(24.2)$ & $170(72.8)$ & \\
\hline $40-50$ & $40(32.9)$ & $75(65.8)$ & \\
\hline Monthly income (PhP) & & & $<0.01$ \\
\hline $0-3800$ & $129(30.6)$ & $322(67.4)$ & \\
\hline $3801-5999$ & $110(27.1)$ & $287(72.0)$ & \\
\hline $6000-8999$ & $185(39.4)$ & $322(58.8)$ & \\
\hline $9000-15,999$ & $152(34.4)$ & $311(64.1)$ & \\
\hline $16,000+$ & $187(43.2)$ & $258(55.0)$ & \\
\hline Employment status of mother & & & 0.97 \\
\hline Employed & $701(35.2)$ & $1392(63.1)$ & \\
\hline Unemployed & $62(35.3)$ & $108(63.6)$ & \\
\hline Employment status of partner & & & 0.46 \\
\hline Employed & $681(35.6)$ & $1343(62.8)$ & \\
\hline Unemployed & $33(40.4)$ & $50(58.7)$ & \\
\hline Marital status & & & 0.20 \\
\hline Married/Living together & $712(35.7)$ & $1390(62.6)$ & \\
\hline Never married/separated/divorced/widowed & $50(29.7)$ & $107(68.5)$ & \\
\hline Combined variable for civil status and employment status of partner & & & 0.32 \\
\hline Single mother & $50(29.7)$ & $107(68.5)$ & \\
\hline Has employed partner/spouse & $679(35.6)$ & $1339(62.8)$ & \\
\hline Has unemployed/partner/spouse & $33(40.4)$ & $50(58.7)$ & \\
\hline Membership in 4Ps & & & 0.04 \\
\hline No & $614(36.7)$ & $1171(61.5)$ & \\
\hline Yes & $148(30.2)$ & $327(68.9)$ & \\
\hline Prenatal care provider & & & 0.75 \\
\hline Doctor/Nurse/Midwife & $741(35.4)$ & $1457(63.1)$ & \\
\hline None/Traditional Birth Attendant & $20(32.3)$ & $37(63.7)$ & \\
\hline Mode of delivery & & & $<0.01$ \\
\hline Normal & $627(32.0)$ & $1446(66.7)$ & \\
\hline
\end{tabular}


Table 2 Cross-tabulations of exposure and probable confounding variables with early initiation of breastfeeding within one hour of birth ( $n=2343)$ (Continued)

\begin{tabular}{|c|c|c|c|}
\hline \multirow{2}{*}{$\frac{\text { Variable/Category }}{\text { Caesarean/other }}$} & \multicolumn{2}{|c|}{ Initiation of breastfeeding ${ }^{a}$} & \multirow[t]{2}{*}{$p$-value } \\
\hline & $132(68.9)$ & $49(26.8)$ & \\
\hline Birth attendant & & & 0.02 \\
\hline Skilled & $606(37.1)$ & $1137(61.0)$ & \\
\hline Traditional birth attendant/none/self/relatives/underboard midwife & $149(29.1)$ & $348(69.9)$ & \\
\hline Place of delivery & & & $<0.01$ \\
\hline Home-based & $192(28.5)$ & $456(70.6)$ & \\
\hline Government healthcare facility & $462(36.7)$ & $926(61.8)$ & \\
\hline Private healthcare facility & $103(47.9)$ & $110(57.9)$ & \\
\hline Sex of child & & & 0.72 \\
\hline Boy & $381(34.7)$ & $763(63.6)$ & \\
\hline Girl & $382(35.8)$ & $737(62.7)$ & \\
\hline Month when prenatal care was first availed $(n=2274)$ & & & $0.70^{\mathrm{b}}$ \\
\hline Maternal knowledge score $(n=2202)$ & & & $<0.01^{\mathrm{b}}$ \\
\hline Number of living older siblings ( $n=2338$ ) & & & $0.01^{b}$ \\
\hline Household size $(n=2343)$ & & & $0.99^{\mathrm{b}}$ \\
\hline
\end{tabular}

${ }^{a}$ Has missing data so frequencies are not equal to 2343 and row percentages are not equal to $100 \%$

${ }^{b} p$-value from Wilcoxon rank-sum test

only $2027(87.5 \%)$ respondents were included in the final analysis.

In our final regression model for early initiation of breastfeeding, there was a departure from the linearity assumption for maternal age $(p=0.02)$ and monthly income $(p<0.01)$. Stratum-specific adjusted odds ratios (aORs) for these variables are presented in the tables. However, there was no evidence of interaction between prenatal visits by a peer counselor and membership in breastfeeding in support groups on early initiation of breastfeeding $(p=0.20)$, thus we did not include interaction terms in our final models. After adjusting for confounders, the odds of early initiation of breastfeeding is $1.32(95 \%$ CI $0.96,1.80)$ times higher among mothers who were visited by a peer counselor during their prenatal period compared to those who were not visited. On the other hand, members of breastfeeding support groups have $49 \%$ greater odds (OR 1.49; 95\% CI 1.12, 1.98) of initiating breastfeeding within 1 $\mathrm{h}$ of child's birth compared to non-members of breastfeeding support groups. Thus, there is insufficient evidence to show that visits by a peer counselor was associated with increased odds of early initiation of breastfeeding, but there is strong evidence that membership in breastfeeding support groups was associated with early initiation of breastfeeding.

\section{Associations with EBF at six months}

Among the probable confounders considered, only birth attendant, and early initiation of breastfeeding were found to have strong evidence of association with EBF, while household size and prenatal care provider were of borderline significance (Table 4). Without adjusting for confounding, visits by peer counselors during pregnancy increased the odds of EBF by $15 \%$ (cOR 1.15; 95\% CI 0.90, 1.47), and visits by peer counselors after delivery increased the odds of EBF by $28 \%$ (cOR 1.28; 95\% CI $0.97,1.70$ ), but the evidence for these associations were not strong. Meanwhile, membership in breastfeeding support groups (COR 1.73; 95\% CI 1.32, 2.27) was strongly associated with EBF (Table 5).

Aside from the probable confounders which were identified to be associated with peer counselor visits during pregnancy, we also found the variables place of residence, prenatal care provider, and early initiation of breastfeeding to be strongly associated with peer counselor visits after delivery (Additional file 5). Thus, birth attendant, household size, early initiation of breastfeeding, and prenatal care provider satisfied the definition of a confounder in our data and would be included in the EBF model. Other known confounders from the literature, such as maternal civil status, mode of delivery, maternal age, number of living older siblings, and monthly income, and employment status of mother, and sex of infant, were also forced into the model. As with the early initiation of breastfeeding model, we used the combined variable of maternal marital status and partner employment, and the combined variable of place of delivery and birth attendant in modelling the association between receiving JP interventions (prenatal and postnatal counselor visits, and breastfeeding support groups) and exclusive breastfeeding. We also excluded from the regression analysis some 276 respondents with 
Table 3 Crude and adjusted association of peer counselor visits during prenatal period and membership in breastfeeding support groups with early initiation of breastfeeding within $1 \mathrm{~h}$ of birth

\begin{tabular}{|c|c|c|c|c|}
\hline Variable/Category & cOR and $95 \%$ & $p$-value & aOR and $95 \% \mathrm{Cl}^{\mathrm{a}}$ & $p$-value \\
\hline \multicolumn{5}{|l|}{ Visit by a peer counselor during prenatal period } \\
\hline No & 1 (baseline) & & 1 (baseline) & \\
\hline Yes & $1.48(1.16,1.88)$ & $<0.01$ & $1.32(0.96,1.80)$ & 0.08 \\
\hline \multicolumn{5}{|l|}{ Membership in breastfeeding support groups } \\
\hline No & 1 (baseline) & & 1 (baseline) & \\
\hline Yes & $1.56(1.17,2.08)$ & $<0.01$ & $1.49(1.12,1.98)$ & $<0.01$ \\
\hline \multicolumn{5}{|l|}{ Age group } \\
\hline $15-19$ & 1 (baseline) & & 1 (baseline) & \\
\hline $20-24$ & $0.82(0.58,1.16)$ & 0.26 & $0.85(0.55,1.30)$ & 0.44 \\
\hline $25-29$ & $0.98(0.68,1.40)$ & 0.91 & $1.08(0.66,1.77)$ & 0.74 \\
\hline $30-34$ & $0.67(0.46,0.95)$ & 0.03 & $0.71(0.41,1.24)$ & 0.23 \\
\hline $35-39$ & $1.49(0.96,2.32)$ & 0.08 & $1.23(0.68,2.24)$ & 0.48 \\
\hline $40-50$ & $0.99(0.58,1.69)$ & 0.97 & $0.81(0.39,1.68)$ & 0.22 \\
\hline \multicolumn{5}{|l|}{ Monthly income } \\
\hline $0-3800$ & 1 (baseline) & & 1 (baseline) & \\
\hline $3801-5999$ & $1.21(0.76,1.92)$ & 0.42 & $1.41(0.89,2.23)$ & 0.14 \\
\hline $6000-8999$ & $0.68(0.47,0.97)$ & 0.04 & $0.83(0.60,1.15)$ & 0.26 \\
\hline $9000-15,999$ & $0.85(0.59,1.21)$ & 0.36 & $1.16(0.78,1.72)$ & 0.46 \\
\hline $16,000+$ & $0.58(0.40,0.84)$ & $<0.01$ & $0.83(0.61,1.13)$ & 0.22 \\
\hline \multicolumn{5}{|l|}{ Combined variable for place of delivery and birth attendant } \\
\hline Home birth; skilled birth attendant & 1 (baseline) & & 1 (baseline) & \\
\hline Home birth; unskilled birth attendant & $1.05(0.64,1.71)$ & 0.85 & $0.73(0.40,1.34)$ & 0.31 \\
\hline Government healthcare facility birth; skilled birth attendant & $0.71(0.45,1.12)$ & 0.14 & $0.84(0.51,1.38)$ & 0.49 \\
\hline Private healthcare facility birth; skilled birth attendant & $0.41(0.23,0.72)$ & $<0.01$ & $0.61(0.30,1.24)$ & 0.17 \\
\hline Number of living older siblings of the index child & $1.07^{\mathrm{b}}(1.01,1.15)$ & 0.03 & $1.04(0.95,1.13)$ & 0.40 \\
\hline Maternal knowledge score & $1.33^{b}(1.19,1.48)$ & $<0.01$ & $1.30(1.13,1.49)$ & $<0.01$ \\
\hline \multicolumn{5}{|l|}{ Mode of delivery } \\
\hline Normal & 1 (baseline) & & 1 (baseline) & \\
\hline Caesarean/other & $0.19(0.12,0.28)$ & $<0.01$ & $0.20(0.13,0.32)$ & $<0.01$ \\
\hline \multicolumn{5}{|l|}{ Place of residence } \\
\hline Urban & 1 (baseline) & & 1 (baseline) & \\
\hline Rural & $1.89(1.06,3.35)$ & 0.03 & $1.54(0.90,2.62)$ & 0.11 \\
\hline \multicolumn{5}{|l|}{ Employment status of mother } \\
\hline Employment & 1 (baseline) & & 1 (baseline) & \\
\hline Unemployment & $1.01(0.70,1.44)$ & 0.97 & $0.97(0.68,1.38)$ & 0.86 \\
\hline \multicolumn{5}{|l|}{ Sex of child } \\
\hline Boy & 1 (baseline) & & 1 (baseline) & \\
\hline Girl & $0.96(0.75,1.22)$ & 0.71 & $1.07(0.82,1.39)$ & 0.63 \\
\hline
\end{tabular}

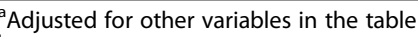

${ }^{\mathrm{b}} \mathrm{Common}$ odds ratio showing increase in odds per unit increase in level of the variable

incomplete data in all the remaining variables of interest, thus our final sample for this analysis was 1589 (86.7\%).

In our final model for EBF, we noted that there was no departure from the linearity assumption for age group $(p=0.88)$ and monthly income $(p=0.93)$; thus, only common aORs were reported. There were also no significant two-way or three-way statistical interactions between prenatal peer counselor visits, postnatal peer 
Table 4 Cross-tabulations of exposure and probable confounding variables with exclusive breastfeeding at 6 months

\section{Variable/Category}

Visit by a peer counselor during prenatal period

No

Yes

Membership in breastfeeding support groups

No

Yes

Visited by a peer counselor after delivery

No

Yes

Place of residence

Urban area

Rural area

Age of mothers in years
15-19
20-24
25-29
30-34
35-39
40-50

Monthly income (PhP)

$$
\begin{aligned}
& 0-3800 \\
& 3801-5999 \\
& 6000-8999 \\
& 9000-15,999 \\
& 16,000+
\end{aligned}
$$

Employment status of mother

$$
\text { Employed }
$$$$
\text { Unemployed }
$$

Employment status of partner

$$
\begin{aligned}
& \text { Employed } \\
& \text { Unemployed }
\end{aligned}
$$

Marital status

Married/Living together

Never married/separated/divorced/widowed

Combined variable for civil status and employment status of partner

Single mother

Has employed partner/spouse

Has unemployed partner/spouse

Membership in 4Ps

No

Yes

Prenatal care provider

Doctor/Nurse/Midwife

None/Traditional Birth Attendant
Exclusive breastfeeding at six months ${ }^{\mathrm{a}}$

No

$p$-value

895 (63.2)

$248(60.9)$

$858(66.7)$

$292(54.8)$

$890(64.0)$

$258(59.4)$

$1040(63.9)$

$115(58.8)$

81 (65.6)

$308(62.9)$

$315(62.7)$

$256(60.5)$

$125(61.8)$

65 (68.6)

$223(59.7)$

$186(59.2)$

266 (61.8)

242 (66.2)

$238(66.5)$

1065 (62.7)

90 (63.1)

1025 (62.5)

$43(59.0)$

1065 (62.3)

87 (68.1)

87 (68.1)

1021 (62.4)

$43(59.0)$

922 (63.4)

$232(60.8)$

1117 (62.2)

33 (76.8)

Yes

469 (34.0)

148 (37.6)

410 (30.5)

$210(43.3)$

0.27

456 (33.0)

$163(39.2)$

531 (32.9)

90 (40.7)

38 (29.5)

$170(34.3)$

$168(36.3)$

143 (35.9)

73 (36.1)

28 (29.8)

133 (37.8)

$125(38.3)$

149 (36.6)

$117(31.3)$

97 (29.9)

$578(34.7)$

43 (34.8)

557 (35.0)

25 (39.3)

581 (35.2)

39 (29.2)

39 (29.2)

556 (35.0)

25 (39.3)

469 (34.1)

151 (36.8)
611 (35.3)

9 (19.9) 
Table 4 Cross-tabulations of exposure and probable confounding variables with exclusive breastfeeding at 6 months (Continued)

\begin{tabular}{|c|c|c|c|}
\hline \multirow{2}{*}{$\begin{array}{l}\text { Variable/Category } \\
\text { Mode of delivery }\end{array}$} & \multicolumn{2}{|c|}{ Exclusive breastfeeding at six months ${ }^{a}$} & \multirow{2}{*}{$\frac{\boldsymbol{p} \text {-value }}{0.66}$} \\
\hline & & & \\
\hline Normal & $1050(62.7)$ & $575(35.1)$ & \\
\hline Caesarean/other & $99(62.0)$ & $43(31.4)$ & \\
\hline Birth attendant & & & 0.01 \\
\hline Skilled & $897(64.6)$ & $468(32.6)$ & \\
\hline Traditional birth attendant/none/self/relatives/underboard midwife & $247(56.9)$ & $147(41.5)$ & \\
\hline Place of delivery & & & 0.45 \\
\hline Home-based & $325(60.5)$ & $187(37.5)$ & \\
\hline Government healthcare facility & $702(64.1)$ & $385(33.7)$ & \\
\hline Private healthcare facility & $120(63.6)$ & $45(30.6)$ & \\
\hline Sex of child & & & 0.35 \\
\hline Boy & $595(64.1)$ & $307(33.5)$ & \\
\hline Girl & $560(61.3)$ & $314(36.1)$ & \\
\hline Early initiation of breastfeeding & & & $<0.01$ \\
\hline Late & $436(72.2)$ & $153(26.6)$ & \\
\hline Early & $718(59.2)$ & $468(39.9)$ & \\
\hline Month when prenatal care was first availed & & & $0.14^{\mathrm{b}}$ \\
\hline Maternal knowledge score & & & $0.19^{b}$ \\
\hline Number of living older siblings & & & $0.27^{b}$ \\
\hline Household size & & & $0.05^{b}$ \\
\hline
\end{tabular}

${ }^{\mathrm{a}} \mathrm{Has}$ missing data so frequencies are not equal to 2343 and row percentages are not equal to $100 \%$

${ }^{\mathrm{b}} p$-value from Wilcoxon rank-sum test

counselor visits, and membership in breastfeeding support groups which could affect EBF. Specifically, there were also no significant statistical interactions (or synergy) between prenatal and postnatal peer counselor visits $(p=0.35)$, as well as between prenatal peer counselor visits and membership in breastfeeding support groups $(p=0.16)$, postnatal peer counselor visits and membership in breastfeeding support groups $(p=$ $0.74)$, and the three interventions with each other $(p=$ 0.56 ) on exclusive breastfeeding. After adjusting for confounders, we report that there was no strong evidence that visits by peer counselors during pregnancy $(\mathrm{aOR}$ $0.88 ; 95 \%$ CI $0.65,1.20)$ as well as visits after delivery (aOR 1.14; 95\% CI 0.80, 1.63) were associated with EBF. However, being a member in breastfeeding support groups significantly increased the odds of EBF by $65 \%$ (aOR 1.65; 95\% CI 1.20, 2.24) (Table 5).

\section{Discussion}

Our secondary analysis of the Endline Survey data of the JP reveals that $63 \%$ of mothers breastfed within an hour of birth, and only 35\% exclusively breastfed at 6 months, which are both below the DOH targets of $90 \%$ prevalence for early initiation of breastfeeding and $70 \%$ prevalence for EBF. While there is no strong evidence that visits by a peer counselor during pregnancy and after delivery are associated with early initiation of breastfeeding and EBF, there is strong evidence that membership in breastfeeding support groups is positively associated with both early initiation of breastfeeding and EBF. One possible explanation of why membership in breastfeeding support groups was effective in promoting both early initiation of breastfeeding and EBF, while peer counselors only had marginal effectiveness, may be the active knowledge transfer during breastfeeding support group sessions compared to the relatively passive one-on-one lectures in peer counseling sessions. Our secondary analysis did not detect possible synergy (i.e., statistical interaction) between peer counselor visits and membership in breastfeeding support groups, and early initiation of breastfeeding and EBF at 6 months. In other words, the effect of these two specific JP interventions on early initiation of breastfeeding and EBF are probably independent of each other.

Home visits by a peer counselor are designed to encourage mothers to get adequate prenatal care and to advocate for them, and promote the positive effects of early initiation of breastfeeding and EBF. The mothers were also coached by these peer counselors to continue breastfeeding exclusively up to 6 months after birth, to introduce quality complementary food only after 6 months, and to breastfeed beyond 2 years. Breastfeeding 
Table 5 Crude and adjusted association of peer counselor visits during prenatal period, membership in breastfeeding support groups, and peer counselor visits after delivery with exclusive breastfeeding at six months

\begin{tabular}{|c|c|c|c|c|}
\hline Variable/Category & cOR and $95 \% \mathrm{Cl}$ & $p$-value & aOR and $95 \% \mathrm{Cl}$ & $p$-value \\
\hline \multicolumn{5}{|l|}{ Visit by a peer counselor during pre-natal period } \\
\hline No & 1 (baseline) & & 1 (baseline) & \\
\hline Yes & $1.15(0.90,1.47)$ & 0.27 & $0.88(0.65,1.20)$ & 0.42 \\
\hline \multicolumn{5}{|l|}{ Membership in breastfeeding support groups } \\
\hline No & 1 (baseline) & & 1 (baseline) & \\
\hline Yes & $1.73(1.32,2.27)$ & $<0.01$ & $1.65(1.20,2.24)$ & $<0.01$ \\
\hline \multicolumn{5}{|l|}{ Visit by a peer counselor after delivery } \\
\hline No & 1 (baseline) & & 1 (baseline) & \\
\hline Yes & $1.28(0.97,1.70)$ & 0.09 & $1.14(0.80,1.63)$ & 0.47 \\
\hline \multicolumn{5}{|l|}{ Initiation of breastfeeding } \\
\hline Late & 1 (baseline) & & 1 (baseline) & \\
\hline Early & $1.83(1.32,2.53)$ & $<0.01$ & $2.07(1.48,2.89)$ & $<0.01$ \\
\hline \multicolumn{5}{|l|}{ Combined variable for place of delivery and birth attendant } \\
\hline Home birth; skilled birth attendant & 1 (baseline) & & 1 (baseline) & \\
\hline Home birth; unskilled birth attendant & $1.74(1.07,2.82)$ & 0.03 & $1.46(0.87,2.43)$ & 0.15 \\
\hline Government healthcare facility birth; skilled birth attendant & $1.27(0.78,2.06)$ & 0.33 & $1.16(0.70,1.91)$ & 0.56 \\
\hline Private healthcare facility birth; skilled birth attendant & $1.17(0.65,2.09)$ & 0.59 & $1.18(0.62,2.25)$ & 0.62 \\
\hline Household size & $0.94^{\mathrm{b}}(0.89,0.99)$ & 0.03 & $0.92^{\mathrm{b}}(0.85,0.99)$ & 0.03 \\
\hline \multicolumn{5}{|l|}{ Prenatal care provider } \\
\hline Doctor/Nurse/Midwife & 1 (baseline) & & 1 (baseline) & \\
\hline None/Traditional Birth Attendant & $1.16(0.90,1.49)$ & 0.25 & $1.08(0.16,7.55)$ & 0.94 \\
\hline Number of living older siblings & $1.02^{\mathrm{b}}(0.95,1.09)$ & 0.59 & $1.04^{\mathrm{b}}(0.94,1.15)$ & 0.45 \\
\hline \multicolumn{5}{|l|}{ Mode of delivery } \\
\hline Normal & 1 (baseline) & & 1 (baseline) & \\
\hline Caesarean/other & $0.91(0.58,1.42)$ & 0.67 & $1.27(0.79,2.06)$ & 0.32 \\
\hline Age group & $1.00^{\mathrm{b}}(0.98,1.02)$ & & $0.99^{b}(0.96,1.02)$ & 0.47 \\
\hline \multicolumn{5}{|l|}{ Sex of child } \\
\hline Boy & 1 (baseline) & & 1 (baseline) & \\
\hline Girl & $1.13(0.87,1.45)$ & 0.35 & $1.20(0.94,1.55)$ & 0.15 \\
\hline \multicolumn{5}{|l|}{ Combined variable for civil status and employment status of partner } \\
\hline Single mother & 1 (baseline) & & 1 (baseline) & \\
\hline Has employed partner/spouse & $1.31(0.87,1.98)$ & 0.20 & $1.17(0.62,2.23)$ & 0.63 \\
\hline Has unemployed partner/spouse & $1.56(0.79,3.08)$ & 0.20 & $1.62(0.76,3.45)$ & 0.21 \\
\hline Monthly income & $1.00(1.00,1.00)$ & 0.04 & $1.00(1.00,1.00)$ & 0.76 \\
\hline \multicolumn{5}{|l|}{ Employment status of mother } \\
\hline Employed & 1 (baseline) & & 1 (baseline) & \\
\hline Unemployed & $0.99(0.65,1.53)$ & 0.98 & $1.07(0.52,2.19)$ & 0.86 \\
\hline
\end{tabular}

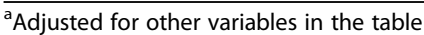

${ }^{\mathrm{b}}$ Common odds ratio showing increase in odds per unit increase in level of the variable

support groups, on the other hand, were organized in the communities to promote proper IYCF practices among the mothers with infants and children less than 2 years old. These support groups were supposed to encourage and support the mothers so they can initiate breastfeeding early and continue breastfeeding their infants exclusively until the baby is 6 months old. Together with proper complementary feeding, members of 
the support groups motivate each other to continue breastfeeding the babies up to 2 years and beyond, if possible, to maximize the positive effects of mothers' milk on young children.

The importance of family- or community-based interventions to improve neonatal and child health cannot be overemphasized. There is evidence that communitybased interventions can reduce all-cause neonatal mortality by $10-50 \%$ [39]. However, studies assessing the effectiveness of these interventions are few and the findings are contradictory [40, 41]. There are also reviews on community-based interventions, optimal feeding practices, and child health. A Cochrane review reported that there is no strong evidence to conclude that non-healthcare professional-led interventions, which include support groups and peer counselors, affect early initiation of breastfeeding among target mothers [42]. Another review identified the following gaps in operations research for community-based interventions to promote child health: [a] how health workers, including non-healthcare professionals, could most effectively deliver the needed services for newborns and children at the community; [b] the scope of service of community health workers; [c] ways to link community health workers with referral facilities to provide care for mothers and children; and [d] how community-based interventions can be managed sustainably [43]. A third review reported that interventions conducted by lay people, especially those providing emotional support and counseling, including services that are given during pregnancy and continued postpartum, are associated with greater odds of EBF. The review concluded that effective interventions to promote EBF should have multiple components, have a clear training protocol to engage both professionals and non-professionals healthcare providers, and have continuity of service between the health facility and the community [44]. The fact that these studies have different results and recommendations could be probably explained by differences in the interventions, the target populations, and the study methods employed.

Our study has a number of important limitations. First, the exact nature of the engagement of peer counselors with the target mothers was not clearly defined and this may explain the lack of association seen between peer counselor visits and early initiation of breastfeeding and EBF. Notably, a fifth of the peer counselors mentioned that they have little or no knowledge on their roles and activities, while another one-third felt that they have inadequate knowledge on what to do if a child is sick [15]. Second, while breastfeeding support groups enjoyed greater acceptance than one-on-one visits by peer counselors, there were also some issues including implementation delays, issues in training and engagement, and the non-mandatory participation of the members. Third, the sample size used in the analyses may have been insufficient for tests of statistical interactions [45]. This partly explains the absence of a statistically significant effect of the hypothesized synergy between the JP interventions that we studied on both early initiation of breastfeeding or EBF at 6 months. Fourth, in assessing the effectiveness of community interventions, a cluster randomized trial would be the more appropriate design to use [46]. However, since the main objective of the JP was to decrease the prevalence of undernutrition and improve the prevalence of optimal breastfeeding practices, and not to assess the effectiveness of interventions, a before-and-after evaluation design with two separate cross-sectional studies was used instead given the available resources. As a result, the issue of reverse causality, which is inherent in crosssectional studies, may affect the internal validity of our analysis [47]. Fifth, differences in the extent of missing outcome data for our different exposure variables could point to possible selection bias: [a] percent of missing early initiation of breastfeeding data is higher among those who were not visited by a peer counselor during prenatal period compared to those who were visited; [b] percent of missing EBF data is higher among members of breastfeeding support groups than those who were not; and $[c]$ percent of those with missing EBF data is higher among those who were visited by a peer counselor after delivery compared to those who were not visited. Sixth, our study may also suffer from information bias since we utilized self-reported data. The findings of our study are, therefore, only as good as the reports of the mothers who took part in the study. Mothers of relatively older infants may be less likely to provide accurate recall as compared to mothers of younger infants and/or newborns [48]. Our study may also have residual confounding because important correlates of the outcome such as educational status of the mother and opinion of other family members were not collected [28]. Lastly, the Endline Survey did not have data on the number of visits of peer counselors, as well as the number of sessions held by the breastfeeding support groups, which prevented us from characterizing the nature of mother-peer counselor dynamics. This information gap also prevented us from exploring possible dose-response relationships between the JP interventions and the outcome variables. Despite this, we controlled for the effect of other important confounders like mode of delivery, maternal age, number of living older siblings, place of delivery and birth attendant.

\section{Conclusions}

Our findings suggest that early initiation of breastfeeding within 1 hour of birth and EBF at 6 months in the 
country do not meet national targets. We also found that there is insufficient evidence that peer counseling during pregnancy and after delivery are associated with early initiation of breastfeeding and EBF, but that there is strong evidence that membership in breastfeeding support groups is positively associated with both early initiation of breastfeeding and EBF at 6 months. Adopting good training designs for community volunteers and conducting regular sessions may make breastfeeding support groups more effective in improving early initiation of breastfeeding and EBF practices. While the role of peer counselors in promoting early initiation of breastfeeding and EBF remains unclear, they may still have a significant role to play in promoting both. We recommend that peer counselors should have clear messages to deliver to target mothers to promote early initiation of breastfeeding, exclusive breastfeeding, and to discuss the importance of prenatal care [49]. Although trained healthcare professionals like midwives and nurses were reported to be more effective in promoting breastfeeding among target mothers, there are not enough of them to do this [42, 44]. This is one area where lay community health workers like breastfeeding counselors can be tapped to carry out some of these functions. Setting performance targets coupled with close supervision, salaries, or incentives are necessary to institutionalize grassroots-level interventions to promote any community-based intervention including optimal breastfeeding practices. These interventions should be supported by the government at all levels through financing, partnerships between local and external stakeholders, and logistical support at all levels to further ensure effective and efficient implementation [50].

Our suggestion to integrate non-healthcare professionals in efforts to promote early initiation of breastfeeding and EBF could be tested further in future intervention studies. Operations research can address various information gaps on child health which could be addressed by doing community trials [51]. This has been emphasized by one Cochrane review which concluded that current evidence on the effectiveness of nonhealthcare professional-led interventions on early initiation of breastfeeding are few and of poor quality [42]. Thus, methodologically sound studies to assess the effectiveness of peer counselors and/or support groups in promoting optimal breastfeeding behaviors are still needed. The need for more research on this topic to influence policies and programs is demonstrated by the low prevalence of early initiation of breastfeeding and exclusive breastfeeding worldwide, including the Philippines.

\section{Abbreviations}

4Ps: Pantawid Pamilyang Pilipino Program; aOR: Adjusted odds ratio; cOR: Crude odds ratio; DOH: Department of Health; EBF: Exclusive breastfeeding at six months of age; FAO: Food and Agriculture Organization; ILO: International Labor Organization; IYCF: Infant and young child feeding: MDG-FJP: Millennium Development Goals Achievement Fund - Joint Programme on Ensuring Food Security and Nutrition for Children 0-24 months old in the Philippines; MDG: Millennium Development Goal; OR: Odds ratio; UNICEF: United Nations Children's Fund; WFP: World Food Program; WHO: World Health Organization

\section{Supplementary Information}

The online version contains supplementary material available at https://doi. org/10.1186/s13006-021-00400-5.

\begin{abstract}
Additional file 1. Detailed description of assessed interventions. A more detailed description of the interventions (peer counselor visits before and after delivery and breastfeeding support groups) being assessed containing recruitment procedures, training and compensation, and other implementation details.

Additional file 2. Regression analyses. Detailed description of how regression analyses was carried out, including variable selection procedures.
\end{abstract}

Additional file 3. Cross-tabulations and crude odds ratios of categorical variables with visit by a peer counselor during prenatal period. Crosstabulations and crude odds ratios of outcomes and probable confounders with visit by peer counselor during prenatal period as part of the assessment of potential confounding effects.

Additional file 4. Cross-tabulations and crude odds ratios of categorical variables with membership in breastfeeding support groups. Crosstabulations and crude odds ratios of outcomes and probable confounders with membership in breastfeeding support groups as part of the assessment of potential confounding effects.

Additional file 5. Cross-tabulations and crude odds ratios of categorical variables with visit by a peer counselor after delivery. Cross-tabulations and crude odds ratios of outcomes and probable confounders with visit by a peer counselor after delivery as part of the assessment of potential confounding effects.

\section{Acknowledgements}

We acknowledge the assistance of the local government officials for their support in facilitating fieldwork. We are grateful for the assistance of the Dr. Pura Rayco-Solon of UNICEF Philippines for her assistance throughout the life of the project. We would also like to express our gratitude to Ms. May Lebanan, Ms. Maylin Palatino, Ms. Kim Cochon, and Dr. Venus Oliva Cloma-Rosales for their inputs on the analysis and writing of the early version of the paper. Finally, we thank the children, their mothers, and legal child caregivers for their participation in the study. We also acknowledge the publication support we received from the University of the Philippines Manila (UP Manila) and the Department of Science and Technology - Philippine Council for Health Research and Development (DOST-PCHRD).

\section{Authors' contributions}

OPS conceptualized the study with the project's senior investigators and acquired funding. OPS, with the assistance of the entire project staff, carried out the investigation and supervision of the entire study. VCFP, and AMLA were responsible for data curation, validation, and data analyses. VCFP and AMLA wrote the first draft of the paper. OPS reviewed and edited the manuscript. All authors approved the final version of the manuscript.

\section{Funding}

The United Nations Children's Fund (UNICEF), the Global Alliance for Improved Nutrition (GAIN), the World Health Organization (WHO) and the World Food Programme (WFP) provided financial and/or technical support to this study.

\section{Availability of data and materials}

The datasets used and/or analyzed during the current study are available from the corresponding author (opsaniel@up.edu.ph) on reasonable request. 


\section{Declarations}

\section{Ethics approval and consent to participate}

The study received ethical approval from the research ethics committees of the three institutions: Bicol Medical Center, Western Visayas Health Research and Development Consortium, and the Zamboanga Consortium for Health Research and Development.

\section{Consent for publication}

The participants consented to the publication and dissemination of study findings.

\section{Competing interests}

The authors have no competing interests to declare.

\section{Author details}

${ }^{1}$ College of Public Health, University of the Philippines Manila, 625 Pedro Gil St., Ermita, Manila, Philippines. ${ }^{2}$ Symmetrix Research Consultancy Company, Manila, Philippines. ${ }^{3}$ School of Medicine and Public Health, Ateneo de Manila University, Ortigas Ave., Pasig City, Philippines.

Received: 24 July 2020 Accepted: 28 June 2021

Published online: 12 July 2021

\section{References}

1. Victora CG, Bahl R, Barros AJD, França GVA, Horton S, Krasevec J, et al. Breastfeeding in the 21st century: epidemiology, mechanisms, and lifelong effect. Lancet. 2016;387(10017):475-90. https://doi.org/10.1016/S0140-6736(1 5)01024-7.

2. Smith ER, Hurt L, Chowdhury R, Sinha B, Fawzi W, Edmond KM, et al. Delayed breastfeeding initiation and infant survival: A systematic review and meta-analysis. PLoS One. 2017;12(7):e0180722. https://doi.org/10.1371/journa I.pone.0180722.

3. Khan J, Vesel L, Bahl R, Martines JC. Timing of breastfeeding initiation and exclusivity of breastfeeding during the first month of life: effects on neonatal mortality and morbidity--a systematic review and meta-analysis. Matern Child Health J. 2015;19(3):468-79. https://doi.org/10.1007/s10995014-1526-8.

4. UNICEF, WHO. Capture the moment: early initiation of breastfeeding: the best start for every newborn. 2018. https://www.unicef.org/publications/ index_102949.html.

5. Edmond KM, Zandoh C, Quigley MA, Amenga-Etego S, Owusu-Agyei S, Kirkwood BR. Delayed breastfeeding initiation increases risk of neonatal mortality. Pediatrics. 2006;117(3):e380-6. https://doi.org/10.1542/peds.2 005-1496.

6. Takahashi K, Ganchimeg T, Ota E, Vogel JP, Souza JP, Laopaiboon M, et al. Prevalence of early initiation of breastfeeding and determinants of delayed initiation of breastfeeding: secondary analysis of the WHO global survey. Sci Rep. 2017;7(1):44868. https://doi.org/10.1038/srep44868.

7. Matanda DJ, Mittelmark MB, Urke HB, Amugsi DA. Reliability of demographic and socioeconomic variables in predicting early initiation of breastfeeding: a replication analysis using the Kenya demographic and health survey data. BMJ Open. 2014:4(6):e005194. https://doi.org/10.1136/ bmjopen-2014-005194

8. World Health Organization - Western Pacific Region, Department of Health (Philippines). Breastfeeding in the Philippines: A critical review: World Health Organization - Western Pacific Region; 2015. https://apps.who.int/iris/bitstrea m/handle/10665/208256/9789290617273_eng.pdf?sequence=1\&isAllowed= y. Accessed 20 July 2020.

9. Dewey KG, Cohen RJ, Brown KH, Rivera LL. Effects of exclusive breastfeeding for four versus six months on maternal nutritional status and infant motor development: results of two randomized trials in Honduras. J Nutr. 2001; 131(2):262-7. https://doi.org/10.1093/jn/131.2.262.

10. Jedrychowski W, Perera F, Jankowski J, Butscher M, Mroz E, Flak E, et al. Effect of exclusive breastfeeding on the development of children's cognitive function in the Krakow prospective birth cohort study. Eur J Pediatr. 2012; 171(1):151-8. https://doi.org/10.1007/s00431-011-1507-5.

11. Nigatu D, Azage M, Motbainor A. Effect of exclusive breastfeeding cessation time on childhood morbidity and adverse nutritional outcomes in Ethiopia: analysis of the demographic and health surveys. PLoS One. 2019;14: e0223379.
12. Dieterich CM, Felice JP, O'Sullivan E, Rasmussen KM. Breastfeeding and health outcomes for the mother-infant dyad. Pediatr Clin N Am. 2013;60(1): 31-48. https://doi.org/10.1016/j.pcl.2012.09.010.

13. UNICEF. From the first hour of life - Making the case for improved infant and young child feeding everywhere. 2016. https://www.unicef.org/publica tions/index 93027.html.

14. Philippine Statistics Authority (PSA), ICF International. National Demographic and Health Survey (Philippines) 2013. 2014.

15. Chiwara R, Villate E. Final evaluation of the joint Programme: ensuring food security and nutrition for children 0-24 months in the Philippines (MDG-F 2030). 2013. https://www.unicef.org/evaldatabase/files/Philippines_2013001_Final_report_MDGF_2030_22072013.pdf.

16. Pastores MC, Sanguyo JD, Garg A, Parreno M, Kitong J, Vega ML. Ensuring food security and nutrition for children 0-24 months old in the Philippines. 2015. http://www.unscn.org/files/UNSCN_Meeting_Bangkok_2015/DAY_2 Morning_Philippines_Joint_Nutrition_Programming_MDG-F_Maria_Cecilia_ Pastores.pdf.

17. Adugna DT. Women's perception and risk factors for delayed initiation of breastfeeding in Arba Minch Zuria, Southern Ethiopia. Int Breastfeed J. 2014; 9(1):8. https://doi.org/10.1186/1746-4358-9-8.

18. Ahmed AE, Salih OA. Determinants of the early initiation of breastfeeding in the Kingdom of Saudi Arabia. Int Breastfeed J. 2019;14(1):13. https://doi. org/10.1186/s13006-019-0207-z.

19. Adhikari M, Khanal V, Karkee R, Gavidia T. Factors associated with early initiation of breastfeeding among Nepalese mothers: further analysis of Nepal demographic and health survey, 2011. Int Breastfeed J. 2014;9(1):21. https://doi.org/10.1186/s13006-014-0021-6.

20. Victor R, Baines SK, Agho KE, Dibley MJ. Determinants of breastfeeding indicators among children less than 24 months of age in Tanzania: a secondary analysis of the 2010 Tanzania demographic and health survey. BMJ Open. 2013;3(1):e001529. https://doi.org/10.1136/bmjopen-2012-001529.

21. Heck KE, Braveman P, Cubbin C, Chávez GF, Kiely JL. Socioeconomic status and breastfeeding initiation among California mothers. Public Health Rep. 2006:121(1):51-9. https://doi.org/10.1177/003335490612100111.

22. Lindberg LD. Women's decisions about breastfeeding and maternal employment. J Marriage Fam. 1996;58(1):239-51. https://doi.org/10.2307/3 53392.

23. Khan GN, Ariff S, Khan U, Habib A, Umer M, Suhag Z, et al. Determinants of infant and young child feeding practices by mothers in two rural districts of Sindh, Pakistan: a cross-sectional survey. Int Breastfeed J. 2017;12:40.

24. Kornides M, Kitsantas P. Evaluation of breastfeeding promotion, support, and knowledge of benefits on breastfeeding outcomes. J Child Health Care. 2013;17(3):264-73. https://doi.org/10.1177/1367493512461460.

25. Yılmaz E, Doğa Öcal F, Vural Yılmaz Z, Ceyhan M, Kara OF, Küçüközkan T. Early initiation and exclusive breastfeeding: factors influencing the attitudes of mothers who gave birth in a baby-friendly hospital. Turk J Obstet Gynecol. 2017;14(1):1-9. https://doi.org/10.4274/tjod.90018.

26. Ulep VGT, Borja MP. Association between pregnancy intention and optimal breastfeeding practices in the Philippines: a cross-sectional study1. BMC Pregnancy Childbirth. 2012;12(1):69. https://doi.org/10.1186/1471-2393-12-69.

27. Alzaheb RA. A review of the factors associated with the timely initiation of breastfeeding and exclusive breastfeeding in the Middle East. Clin Med Insights Pediatr. 2017;11:11795565177488912

28. Sharma IK, Byrne A. Early initiation of breastfeeding: a systematic literature review of factors and barriers in South Asia. Int Breastfeed J. 2016:11(1):17. https://doi.org/10.1186/s13006-016-0076-7.

29. Elyas L, Mekasha A, Admasie A, Assefa E. Exclusive breastfeeding practice and associated factors among mothers attending private pediatric and child clinics, Addis Ababa, Ethiopia: A cross-sectional study. Int J Pediatr. 2017; 2017:8546192.

30. Kandeel WA, Rabah TM, Zeid DA, El-Din EMS, Metwally AM, Shaalan A, et al. Determinants of exclusive breastfeeding in a sample of Egyptian infants. Open Access Maced J Med Sci. 2018;6(10):1818-23. https//doi.org/10.3889/oamjms.2018.359.

31. Mundagowa PT, Chadambuka EM, Chimberengwa PT, Mukora-Mutseyekwa F. Determinants of exclusive breastfeeding among mothers of infants aged 6 to 12 months in Gwanda District, Zimbabwe. Int Breastfeed J. 2019;14(1): 30. https://doi.org/10.1186/s13006-019-0225-x

32. Rahman MA, Khan MN, Akter S, Rahman A, Alam MM, Khan MA, et al. Determinants of exclusive breastfeeding practice in Bangladesh: evidence from nationally representative survey data. PLoS One. 2020;15(7):e0236080. https://doi.org/10.1371/journal.pone.0236080. 
33. Balogun OO, Dagvadorj A, Anigo KM, Ota E, Sasaki S. Factors influencing breastfeeding exclusivity during the first 6 months of life in developing countries: a quantitative and qualitative systematic review. Matern Child Nutr. 2015;11(4):433-51. https://doi.org/10.1111/mcn.12180.

34. Abada TSJ, Trovato F, Lalu N. Determinants of breastfeeding in the Philippines: a survival analysis. Soc Sci Med. 2001;52(1):71-81. https://doi. org/10.1016/S0277-9536(00)00123-4.

35. Rohner F, Bradley AW, Grant JA, Elizabeth AY, Lebanan MAO, Rayco-Solon P, et al. Infant and young child feeding practices in urban Philippines and their associations with stunting, Anemia, and deficiencies of Iron and vitamin a. Food Nutr Bull. 2013;34(2_suppl1):S17-34. https://doi.org/10.11 77/15648265130342S104.

36. Department of Social Welfare and Development (Philippines). Pantawid Pamilyang Pilipino Program. 2019. Available from: https://pantawid.dswd. gov.ph/.

37. Clayton D, Hills M. Statistical models in epidemiology. Oxford: Oxford University Press; 1993.

38. StataCorp. Stata 14.0 IC. College Station: StataCorp; 2015.

39. Darmstadt GL, Bhutta ZA, Cousens S, Adam T, Walker N, de Bernis L, et al. Evidence-based, cost-effective interventions: how many newborn babies can we save? Lancet. 2005;365(9463):977-88. https://doi.org/10.1016/S01406736(05)71088-6.

40. Rana MM, Ngoc HNV, TN. Effectiveness of a community-based infant and young child feeding support group programme among ethnic minorities in Vietnam. Field Exchange. 2018:58:71.

41. Kushwaha KP, Sankar J, Sankar MJ, Gupta A, Dadhich JP, Gupta YP, et al. Effect of peer counselling by mother support groups on infant and young child feeding practices: the Lalitpur experience. PLoS One. 2014;9(11): e109181. https://doi.org/10.1371/journal.pone.0109181.

42. Balogun OO, O'Sullivan EJ, McFadden A, Ota E, Gavine A, Garner CD, et al. Interventions for promoting the initiation of breastfeeding. Cochrane Database Syst Rev. 2016;11:CD001688.

43. Bhutta ZA, Darmstadt GL, Hasan BS, Haws RA. Community-based interventions for improving perinatal and neonatal health outcomes in developing countries: a review of the evidence. Pediatrics. 2005; 115(Supplement 2):519-617. https://doi.org/10.1542/peds.2004-1441.

44. Kim SK, Park S, Oh J, Kim J, Ahn S. Interventions promoting exclusive breastfeeding up to six months after birth: a systematic review and metaanalysis of randomized controlled trials. Int J Nurs Stud. 2018:80:94-105. https://doi.org/10.1016/j.jinurstu.2018.01.004

45. Marshall SW. Power for tests of interaction: effect of raising the type I error rate. Epidemiol Perspect Innov. 2007;4(1):4. https://doi.org/10.1186/17425573-4-4.

46. Stoney CM, Johnson LL. Chapter 18 - design of clinical trials and studies. In: Gallin $J$, Ognibene $F P$, Johnson $L L$, editors. Principles and practice of clinical research. 4th ed. Boston: Academic Press; 2018. p. 249-68. https://doi.org/1 0.1016/B978-0-12-849905-4.00018-6

47. Marquis GS, Habicht JP, Lanata CF, Black RE, Rasmussen KM. Association of breastfeeding and stunting in Peruvian toddlers: an example of reverse causality. Int J Epidemiol. 1997;26(2):349-56. https://doi.org/10.1093/ije/2 6.2.349.

48. Agampodi SB, Fernando S, Dharmaratne SD, Agampodi TC. Duration of exclusive breastfeeding; validity of retrospective assessment at nine months of age. BMC Pediatr. 2011;11(1):80. https://doi.org/10.1186/1471-2431-11-80.

49. Kuhnt J, Vollmer S. Antenatal care services and its implications for vital and health outcomes of children: evidence from 193 surveys in 69 low-income and middle-income countries. BMJ Open. 2017;7(11):e017122. https://doi. org/10.1136/bmjopen-2017-017122.

50. Sanghvi T, Martin L, Hajeebhoy N, Abrha TH, Abebe Y, Haque R, et al. Strengthening systems to support mothers in infant and young child feeding at scale. Food Nutr Bull. 2013;34(3_suppl2):S156-68. https://doi. org/10.1177/15648265130343S203.

51. Schiffman J, Darmstadt GL, Agarwal S, Baqui AH. Community-based intervention packages for improving perinatal health in developing countries: a review of the evidence. Semin Perinatol. 2010;34(6):462-76. https://doi.org/10.1053/j.semperi.2010.09.008.

\section{Publisher's Note}

Springer Nature remains neutral with regard to jurisdictional claims in published maps and institutional affiliations.

\section{Ready to submit your research? Choose BMC and benefit from:}

- fast, convenient online submission

- thorough peer review by experienced researchers in your field

- rapid publication on acceptance

- support for research data, including large and complex data types

- gold Open Access which fosters wider collaboration and increased citations

- maximum visibility for your research: over $100 \mathrm{M}$ website views per year

At $\mathrm{BMC}$, research is always in progress.

Learn more biomedcentral.com/submissions 